\title{
Incorporation of polyaniline nanofibres on graphene oxide by interfacial polymerization pathway for supercapacitor
}

\author{
Umashankar Male $^{1} \cdot$ Palaniappan Srinivasan $^{1} \cdot$ Bal Sydulu Singu ${ }^{2}$
}

Received: 24 February 2015/Accepted: 21 August 2015/Published online: 21 September 2015

(C) The Author(s) 2015. This article is published with open access at Springerlink.com

\begin{abstract}
The aim of this work is to improve the supercapacitor performance of polyaniline (PANI). Polyaniline nano fibres are incorporated into graphene oxide (GO) layers by interfacial polymerization pathway, wherein PANI fibres are intercalated into GO layers and also cover the GO. PANI-GO hybrid composite is obtained in semicrystalline form with good conductivity $\left(1.7 \mathrm{~S} \mathrm{~cm}^{-1}\right)$. The specific capacitance for PANI-GO $\left(365 \mathrm{~F} \mathrm{~g}^{-1}\right)$ is found to be higher than PANI $\left(280 \mathrm{~F} \mathrm{~g}^{-1}\right)$. At the energy density of $15 \mathrm{~W} \mathrm{~h} \mathrm{~kg}^{-1}$, the power density of PANI-GO $\left(632 \mathrm{~W} \mathrm{~kg}^{-1}\right)$ is higher than PANI $\left(283 \mathrm{~W} \mathrm{~kg}^{-1}\right)$.
\end{abstract}

Keywords Polyaniline-graphene oxide - Supercapacitor · Interfacial polymerization $\cdot$ Morphology

\section{Introduction}

Electrochemical Capacitors also called supercapacitors or ultracapacitors are the energy storage devices, intermediate between high energy density batteries and high power

The work is carried out at Polymers \& Functional Materials Division, CSIR -Indian Institute of Chemical Technology, Hyderabad 500007 , India.

Palaniappan Srinivasan

palani74@rediffmail.com; palaniappan@iict.res.in

Umashankar Male

shankar_715@yahoo.com

1 Polymers \& Functional Materials Division, CSIR-Indian Institute of Chemical Technology, Tarnaka, Hyderabad 500 007, India

2 Department of Chemistry, Osmania University, Hyderabad 500 007, India density capacitors. Carbon, metal oxides and conducting polymers are the active electrode materials used in supercapacitors. Conducting polymers and metal oxides offer high capacitances compared to carbon materials due to faradaic reactions (pseudocapacitors) occurring in the bulk of the material, but suffer from low power density compared to carbon, which stores energy only on the surface (electric double layer capacitor, EDLC). Among the pseudocapacitive materials (metal oxides and conducting polymers), generally, metal oxides are expensive and toxic, whereas the utilization and application of conducting polymers are limited by the relative poor cycling stability owing to the damage of the polymer backbone during the fast redox processes. To develop a supercapacitor with better performance, a combination of carbon-based materials (EDLC) is widely being tried out along with conducting polymers (pseudocapacitive).This hybrid composite materials are expected to give a high-performance characteristics due to the synergistic effects [1,2]. Thus, polyaniline-graphene oxide composite material is anticipated to possess the distinctive properties of both the graphene oxide and the polyaniline, such as good mechanical strength because of the carbon matrix, excellent electrical conductivity due to polyaniline and graphene oxide, and pseudocapacitance due to polyaniline, thus holding a great promise for hybrid supercapacitors.

Among the various conducting polymers, polyaniline is regarded as one of the most promising electrode materials due to high electrochemical activity, environmental stability, biocompatibility, low cost and ease of synthesis. [36]. Graphite oxide (GO), derived from chemically modified graphene, has attracted great interest owing to its many advantages, such as low manufacturing cost, facile mass production, capacitive properties and remarkable mechanical behaviours [7]. Graphite oxide has expanded d-spacing 
Table 1 Literature report of PANI-GO as electrode material for supercapacitor

\begin{tabular}{llllll}
\hline Ref. no. & System & Synthesis method & Electrolyte & Configuration & Specific capacitance $\left(\mathrm{F} \mathrm{g}^{-1}\right)$ \\
\hline 7 & PANI-NFs-GO & Chemical & $1 \mathrm{M} \mathrm{Na}_{2} \mathrm{SO}_{4}$ & Three electrode & $79.5 @ 0.2 \mathrm{Ag}^{-1}$ \\
8 & GO-PANI & Chemical & $1 \mathrm{M} \mathrm{H}_{2} \mathrm{SO}_{4}$ & Three electrode & $42 @ 0.4 \mathrm{Ag}^{-1}$ \\
9 & PANI-GO & Chemical & $1 \mathrm{M} \mathrm{H}_{2} \mathrm{SO}_{4}$ & Three electrode & $746 @ 0.2 \mathrm{Ag}^{-1}$ \\
10 & PG & Chem:1 & $1 \mathrm{M} \mathrm{H}_{2} \mathrm{SO}_{4}$ & Three electrode & $531 @ 0.2 \mathrm{Ag} \mathrm{g}^{-1}$ \\
11 & PANI-g-rGO & Chemical & $1 \mathrm{M} \mathrm{H}_{2} \mathrm{SO}_{4}$ & Three electrode & $250 @ 100 \mathrm{mVs}^{-1}$ \\
12 & GO-PANI & Chemical & $1 \mathrm{M} \mathrm{H}_{2} \mathrm{SO}_{4}$ & Three electrode & $323 @ 0.3 \mathrm{Ag} \mathrm{g}^{-1}$ \\
6 & PANI-GO film & Electrochemical & $0.5 \mathrm{M} \mathrm{H}_{2} \mathrm{SO}_{4}$ & Three electrode & $25 \mathrm{mF} \mathrm{cm}^{-2} @ 5 \mathrm{mVs}^{-1}$ \\
13 & PANI-GONS & Chemical & $1 \mathrm{M} \mathrm{H}_{2} \mathrm{SO}_{4}$ & Three electrode & $547 @ 10 \mu \mathrm{A}$ \\
14 & GO-PANI & Chemical & $1 \mathrm{M} \mathrm{H}_{2} \mathrm{SO}_{4}$ & Three electrode & $773 @ 1 \mathrm{mV} \mathrm{s}^{-1}$ \\
15 & GO-PANI & Electrochemical & $1 \mathrm{M} \mathrm{H}_{2} \mathrm{SO}_{4}$ & Three electrode & $1136 @ 1 \mathrm{mV} \mathrm{s}^{-1}$ \\
16 & PANI-GO & Chemical & $1 \mathrm{M} \mathrm{H}_{2} \mathrm{SO}_{4}$ & Two electrode & $555 @ 0.2 \mathrm{Ag} \mathrm{g}^{-1}$ \\
17 & GO-PANI & Chemical & $1 \mathrm{M} \mathrm{H}_{2} \mathrm{SO}_{4}$ & Two electrode & $425 @ 0.2 \mathrm{Ag} \mathrm{g}^{-1}$ \\
18 & GO-PANI & Chemical & $1 \mathrm{M} \mathrm{H}_{2} \mathrm{SO}_{4}$ & Two electrode & $150 @ 10 \mathrm{mVs}^{-1}$ \\
19 & PANI/GO & Chemical & $1 \mathrm{M} \mathrm{H}_{2} \mathrm{SO}_{4}$ & Two electrode & $355 @ 0.5 \mathrm{Ag} \mathrm{g}^{-1}$ \\
$* *$ & Present work & Chemical & $1 \mathrm{M} \mathrm{H}_{2} \mathrm{SO}_{4}$ & Two electrode & $346 @ 0.5 \mathrm{Ag} \mathrm{g}^{-1}$ \\
\hline
\end{tabular}

and is in intermediate between graphite and individual graphene sheets and it can be easily exfoliated into single or few layer graphene oxide sheets under sonication. A few reports are available on polyaniline graphene oxide composites for supercapacitors [7-19] (Table 1). Most of the methods are concentrated on the characterization of electrode materials in three-electrode configurations [7-15]. However, two-electrode characteristics give more reliable results compared with that of the three-electrode system for practical applications [20].

Unlike the previous reports, herein we report the results for two-electrode cell configuration. In this work, polyaniline-graphene oxide composite (PANI-GO) was prepared via interfacial polymerization pathway, wherein polyaniline nano fibres (PANI) are intercalated into graphene oxide (GO) layers and also covered the GO. Thus, obtained composite material containing $10 \mathrm{wt} \%$ of $\mathrm{GO}$ w.r.t. the amount of aniline used has shown as a good candidate for supercapacitor in symmetric cell configuration.

\section{Experimental}

\section{Materials}

Aniline, sodium nitrate, toluene, hydrogen peroxide $\left(\mathrm{H}_{2} \mathrm{O}_{2}\right)$, hydrochloric acid $(\mathrm{HCl})$ [S. D. Fine Chemicals, India], ammonium persulfate (APS), sulfuric acid $\left(\mathrm{H}_{2} \mathrm{SO}_{4}\right)$ [Rankem, India] and graphite (Sigma-Aldrich, USA) were used as received. Freshly distilled aniline was employed in the reaction. All the reactions were carried out with distilled water and solvents.

\section{Instrumentation}

For conductivity measurements, polymer samples were pressed into discs of $13 \mathrm{~mm}$ in diameter and about $1.5 \mathrm{~mm}$ in thickness under a pressure of $120 \mathrm{~kg} \mathrm{~cm}^{-2}$. Resistance of the pellet was measured by four probe methods using 6220 constant current source and $2182 \mathrm{~A}$ voltmeter (Keithley, Cleveland, Ohio, USA). XRD profiles for the powders were obtained on a Bruker AXS D8 advance X-ray diffractometer (Karlsruhe, Germany) with $\mathrm{Cu} K_{\alpha}$ radiation (land continuous) $(\lambda=0.154 \mathrm{~nm})$ at a scan speed of $0.045^{\circ} \mathrm{min}^{-1}$. Morphology studies of the polymer powder samples were carried out with a Hitachi S-4300 SE/N field emission scanning electron microscope (FESEM) (Hitachi, Tokyo, Japan) operated at $20 \mathrm{kV}$. The polymer powder sample was sputtered on a carbon disc with the help of double-sided adhesive tape. Transmission electron microscopy (TEM) measurement for PANI-GO was carried out with Philips CM200 instrument. Selected Area Electron Diffraction (SAED) was used to verify the crystal structure of PANI-GO.

\section{Preparation of electrode and electrochemical characterization}

The electrodes were fabricated by pressing the polymer samples on stainless steel mesh (316 grade) by the application of $120 \mathrm{~kg} \mathrm{~cm}^{-2}$ of pressure without any additional 
binder. The electrochemical performances of the polymer samples were investigated using two-electrode system Swagelok type cells without a reference electrode. Two electrodes with identical sample were assembled with a cotton cloth separator in an electrolytic solution of aq. $1 \mathrm{M}$ $\mathrm{H}_{2} \mathrm{SO}_{4}$ solution. Cyclic voltammetry and galvanostatic charge-discharge experiments were carried out with a WMPG 1000 multichannel potentiostat/galvanostat (WonA-Tech, Gyeonggi-do, Korea). Cyclic voltammograms (CV) were recorded from -0.2 to $0.6 \mathrm{~V}$ at various sweep rates and charge-discharge experiments were carried out from 0 to $0.6 \mathrm{~V}$ at various current densities. Electrochemical impedance spectroscopy (EIS) measurement was performed with IM6ex (Zahner-Elektrik, Germany) by applying an AC voltage of $5 \mathrm{mV}$ amplitude in the $40 \mathrm{kHz}-$ $10 \mathrm{mHz}$ frequency range at an applied voltage of $0.6 \mathrm{~V}$ using three-electrode cell configuration, i.e., PANI-GO working electrode, platinum counter electrode and calomel electrode as a reference electrode. All electrochemical measurements were carried out at ambient temperature.

\section{Synthesis of graphite oxide}

Graphite oxide was synthesized from natural graphite by a modified Hummers method [21]. Graphite $(1 \mathrm{~g})$ and $\mathrm{NaNO}_{3}(1 \mathrm{~g})$ were mixed with $46 \mathrm{~mL}$ of $98 \% \mathrm{H}_{2} \mathrm{SO}_{4}$ in a $250 \mathrm{~mL}$ round bottom flask. The mixture was kept stirred in an ice bath. Potassium permanganate $(6 \mathrm{~g})$ was added gradually to the suspension under vigorous stirring for a period of $1 \mathrm{~h}$ and the reaction was continued for $4 \mathrm{~h}$ in the ice bath. The reaction system was then stirred at ambient temperature for $48 \mathrm{~h}$. As the reaction progressed, the mixture gradually became pasty, and the colour turned into light brownish. At the end, $25 \mathrm{~mL}$ of $\mathrm{H}_{2} \mathrm{O}_{2}$ was slowly added to the reaction mixture, the colour of the solution changed from brown to yellow. The Graphite oxide was washed with water followed by dilute $\mathrm{HCl}$ and then dried.

\section{Synthesis of polyaniline-graphene oxide}

Graphene oxide solution was prepared by mixing $50 \mathrm{mg}$ of graphite oxide in $30 \mathrm{~mL}$ of ethanol followed by sonication for a period of $30 \mathrm{~min}$. Pre-dissolved solution containing $1.44 \mathrm{~g}$ of ammonium persulfate in $40 \mathrm{~mL}$ of $1 \mathrm{M}$ aqueous $\mathrm{H}_{2} \mathrm{SO}_{4}$ solution was added to the above mixture and stirred till a uniform mixture. Aniline $(0.5 \mathrm{~mL})$ was dissolved in $30 \mathrm{~mL}$ of toluene (organic layer) and transferred to the above aqueous mixture. The resulting reaction mixture was stirred for $24 \mathrm{~h}$ at room temperature. The aqueous layer containing product was separated from the organic layer. The formed precipitate was collected by filtration under vacuum, washed with an ample amount of distilled water and acetone. The powder sample was dried at $50{ }^{\circ} \mathrm{C}$ till a constant weight.

For comparison, polyaniline (PANI) was synthesized by following the above procedure without using graphene oxide.

\section{Results and discussion}

The aim of the present work is to improve the performance of the PANI electrode with the introduction of GO in PANI. GO was prepared by the modified hummers method. PANI-GO was prepared by in situ interfacial polymerization method (Scheme 1), wherein aniline in organic layer was polymerized by APS in presence of GO in aq. $1 \mathrm{M}$ $\mathrm{H}_{2} \mathrm{SO}_{4}$. The values of conductivity for PANI $\left(2.7 \mathrm{~S} \mathrm{~cm}^{-1}\right)$ and PANI-GO $\left(1.7 \mathrm{~S} \mathrm{~cm}^{-1}\right)$ are found to be very nearly the same. Representative structures of graphite, graphene oxide and polyaniline-graphene oxide composite are given in Scheme 2.

Figure 1 shows the X-ray diffractograms of graphite, GO, PANI and PANI-GO. Inter planar distances were calculated according to Braggs equation $n \lambda=2 \mathrm{~d} \sin \theta$, where $n$ is an integer, $\lambda$ is the $\mathrm{x}$-ray wave length (in the case of $\mathrm{Cu} K_{\alpha}$ radiation, $\lambda=0.154 \mathrm{~nm}$ ). XRD patterns of graphite show a peak at $2 \theta=26.4^{\circ}$ with interplanar distance of $0.17 \mathrm{~nm}$; on conversion to $\mathrm{GO}$, peak due to graphite is disappeared and a new peak at $11.14^{\circ}(d=0.4 \mathrm{~nm})$ is observed. The increase in interplanar distance is due to the introduction of oxygen functionalities in between the graphite layers. XRD pattern of PANI shows peaks centred at $2 \theta$ values of $7.8^{\circ}, 14.4^{\circ}, 19.24^{\circ}$ and $25.28^{\circ}$, which are the characteristic Bragg diffractions of PANI [8, 16]. XRD pattern of PANI-GO is more or less similar to that of the XRD of PANI and the absence of GO reflection peak in PANI-GO confirms that graphite oxide is covered by PANI.

FESEM images of GO prepared by modified hummers method show that the GO is present in the form of loosely stacked sheets with curved edges (Fig. 2a).However, PANI synthesized by interfacial polymerization shows nanofiber morphology (Fig. 2b) and is similar to that of the reported PANI [22, 23]. FESEM images of PANI-GO (Fig. 2c, d) composite show that the PANI is present in different types of structures. PANI nanofibres are intercalated into GO layers and also cover the GO. Moreover, two adjacent layers of GO are connected by PANI nanofibres. The exfoliated GO sheets in solution provide large accessible surface for the nucleation of aniline monomer on both surfaces before the polymerization begins. Besides, under acidic conditions, it is expected that the polar epoxy and carboxyl groups of GO function primarily as the charge compensating sites which 


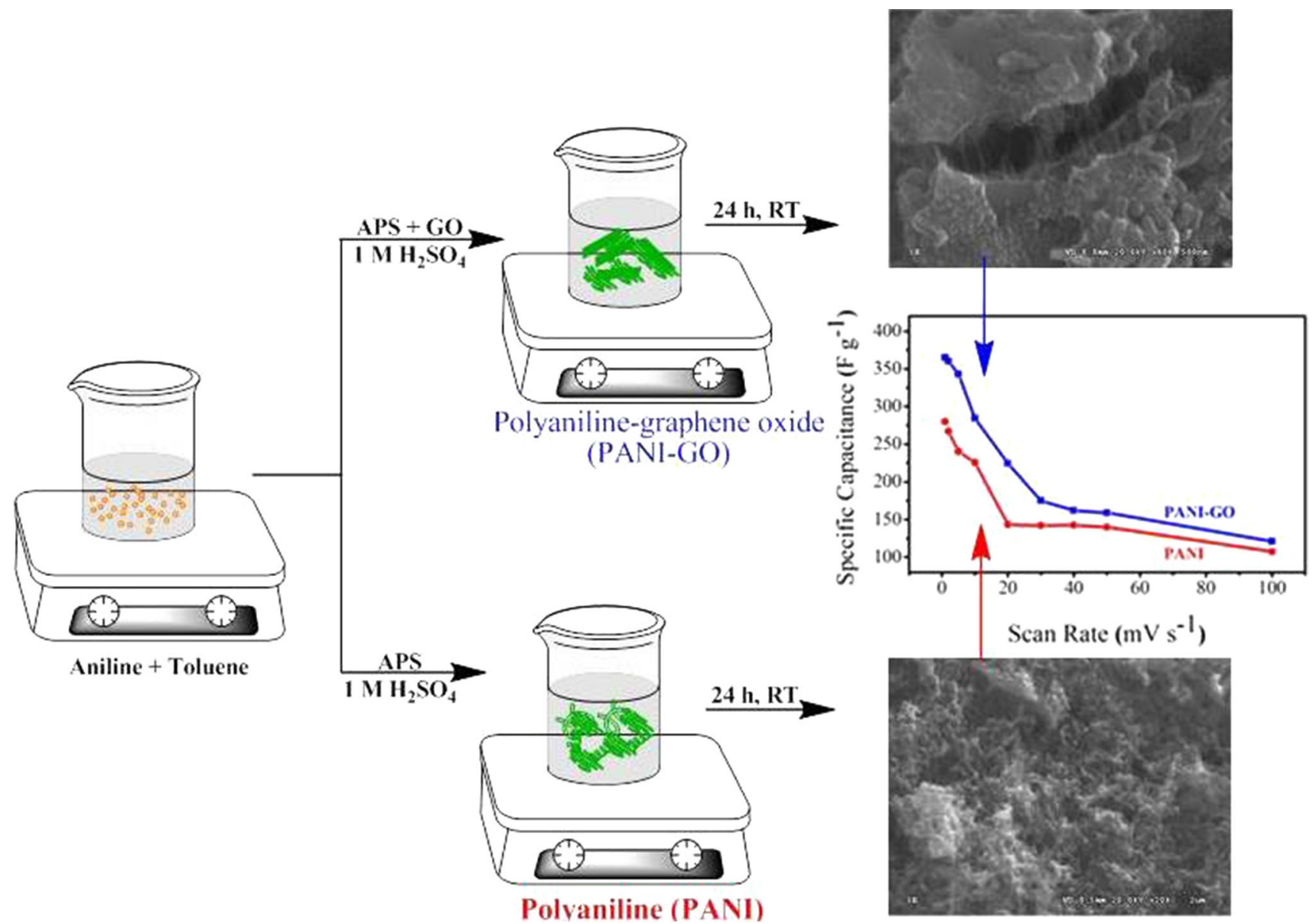

Scheme 1 The schematic representation for interfacial polymerization of PANI-GO and PANI

interact with the radical cations of the $\mathrm{NH}$ groups of PANI $[24,25]$; thus, the composite resulted in uniform coating of PANI on GO. The morphology of PANI-GO clearly indicates that nucleation/growth of the PANI nanofibres occurred on the GO sheets.

The TEM images of the PANI-GO show that the PANI is present in loosely packed nanofibrous morphology as shown in Fig. 3a-c. The loose packing and nanofibrous morphology [26] could help in easy passage of electrolyte ions thereby effective utilization of bulk of the material bulk for redox reactions. Figure $3 \mathrm{a}$, b clearly shows that the PANI nanofibres are present with less than $50 \mathrm{~nm}$ in diameter and a few hundred nano metres in length. Figure $3 c$ shows that the GO is uniformly covered with PANI and also anchors the PANI nanofibres. The strong affinity between the negatively charged carboxyl groups and the positively charged amine nitrogen groups firmly anchors the PANI to the GO sheets [10]. The SAED pattern of PANI-GO, as shown in Fig. 3d, exhibited a ring-shaped pattern with a set of significant diffraction spots but not sharp, indicating the semi-crystalline nature of PANI-GO as seen from XRD.
The above results indicate that during the polymerization of aniline in presence of GO under acidic condition, the polar epoxy and carboxyl groups of GO interact with the radical cations of the $\mathrm{NH}$ groups of PANI, which results in polyaniline salt containing GO as dopant along with sulphuric acid (Scheme 2).

In the supercapacitor performance of PANI-GO, to find out the effect of incorporation of GO in PANI, cyclic voltammetric and charge-discharge experiments were carried out in symmetric cell configuration for PANI-GO and PANI in aqueous $1 \mathrm{M} \mathrm{H}_{2} \mathrm{SO}_{4}$ electrolyte solution.

Figure 4 represents the cyclic voltammograms $(\mathrm{CV})$ of the PANI-GO symmetric supercapacitor cell carried at different sweep rates. The shapes of the cyclic voltammograms are almost rectangular which represents the rapid charge-discharge processes in electrode materials with less internal resistance.

The specific capacitance value from $\mathrm{CV}$ was calculated according to the formula [27].

$C_{\mathrm{s}}=\frac{2 \cdot i_{\mathrm{avg}}}{v \cdot m}$, 


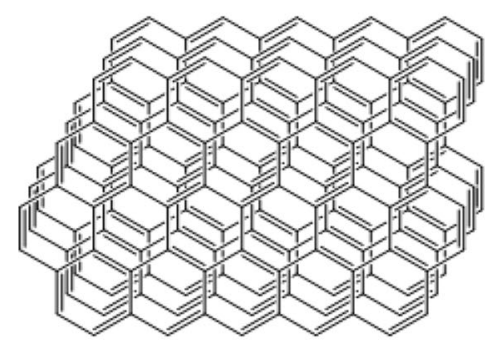

Graphite

\section{(i) Hummers method $\mathrm{NaNO}_{3}, \mathrm{H}_{2} \mathrm{SO}_{4}$ $\mathrm{KMnO}_{4}$}

(ii) Sonication

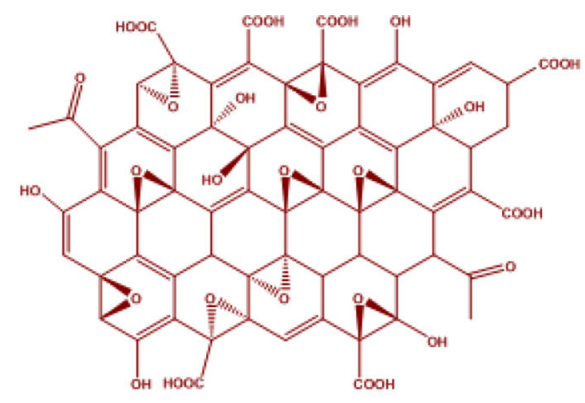

Graphene Oxide

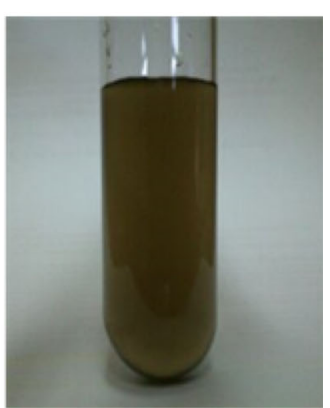

Aniline APS $1 \mathrm{M} \mathrm{H}_{2} \mathrm{SO}_{4}$

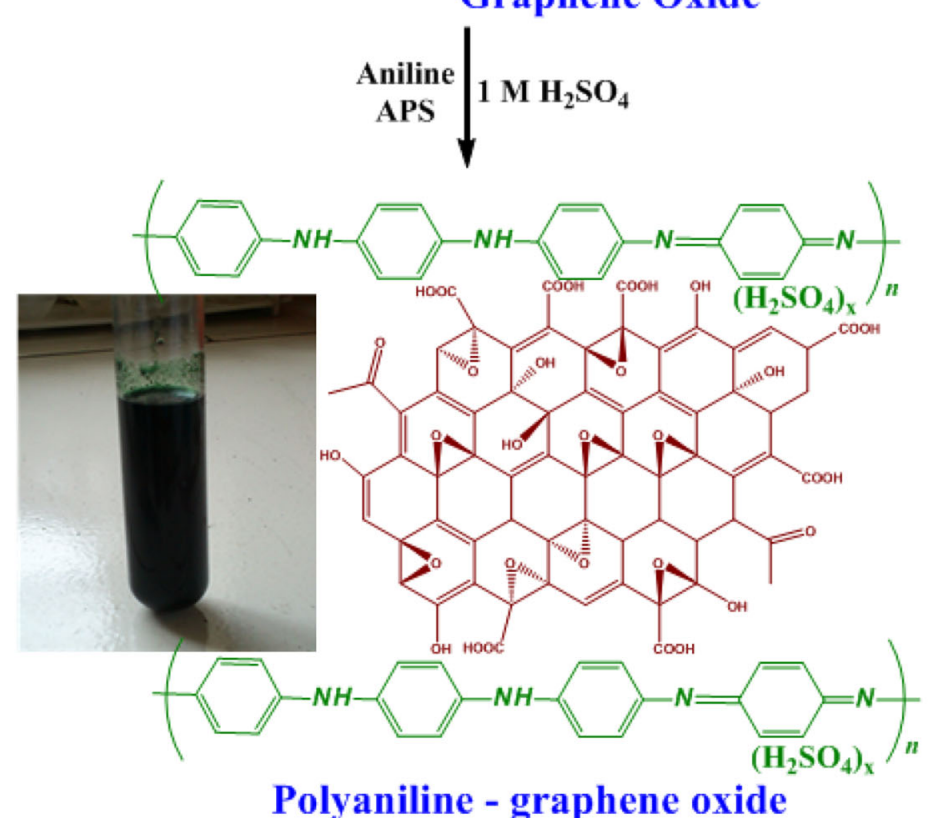

Scheme 2 Representative structures of graphite, its conversion to graphene oxide and then to polyaniline-graphene oxide composite

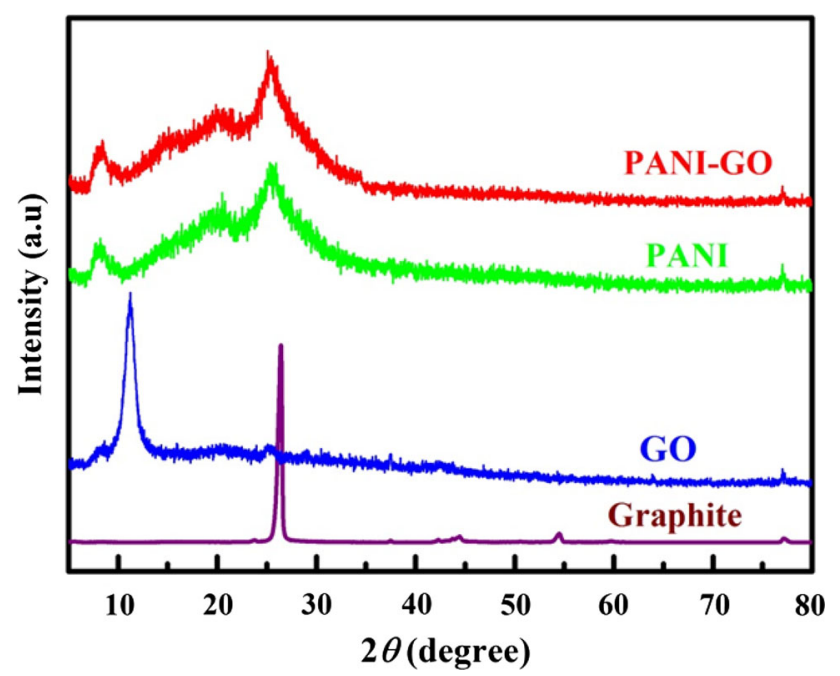

Fig. 1 XRD patterns of graphite, GO, PANI-GO and PANI where $C_{\mathrm{s}}$ is specific capacitance from $\mathrm{CV}, i_{\text {avg }}$ is the average current response of anodic and cathodic curves, $v$ is the potential sweep rate in $\mathrm{mV} \mathrm{s}^{-1}$ and $m$ is the mass of active material in one electrode. To provide a better representation, the $C_{\mathrm{s}}$ values of PANI-GO and PANI are represented in Fig. 5. It is clear from the figure that the $C_{\mathrm{s}}$ values of PANIGO are higher than that of PANI at all sweep rates. The advantages of the composite materials include the following: (1) the GO in the polymer matrix essentially provides rigid support for the stability of the PANI chains during redox cycling, (2) The nanofibrous morphology and readily accessible PANI contribute the overall capacitance to a greater extent (3) The intercalation of PANI avoids the restacking of GO and effectively reduces the dynamic resistance for the passage of electrolyte ions and (4) synergistic effect.

The galvanostatic charge-discharge (CD) curves for PANI-GO cell were carried out at various current densities and are shown in Fig. 6. The good symmetry of CD curves 

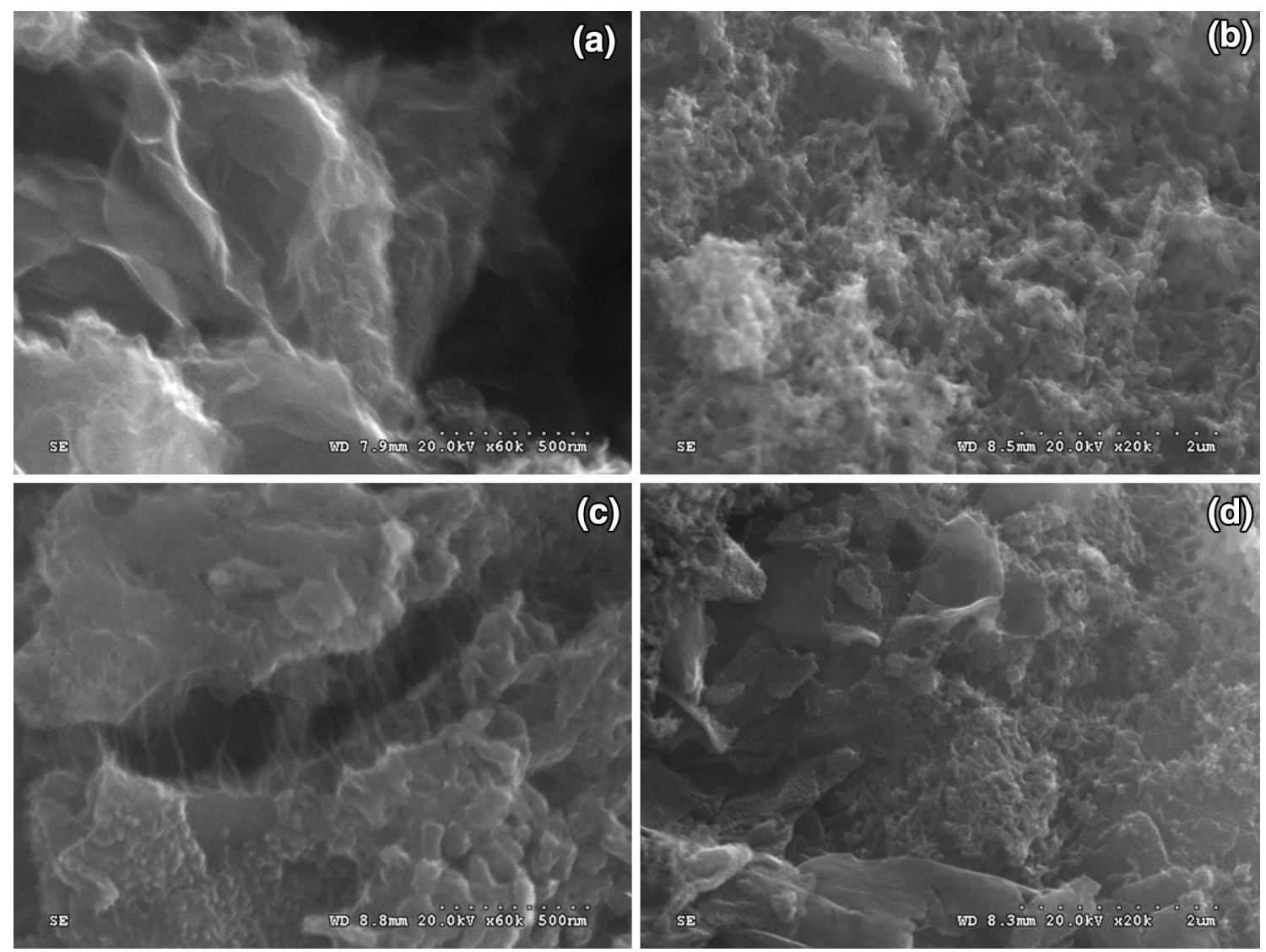

Fig. 2 FESEM pictures of a GO, b PANI and $\mathbf{c}, \mathbf{d}$ PANI-GO

infers that PANI-GO is a good candidate for supercapacitor. A slight deviation in the linear distribution of $C D$ curves is due to the pseudo capacitance, arising from the faradic reaction in the composite material. The specific capacitance from $\mathrm{CD}$ studies $\left(C_{\mathrm{d}}\right)$ is calculated according to the following formula [27].

$C_{\mathrm{d}}=\frac{2 \cdot i \cdot \Delta t}{\Delta E \cdot m}$,

where $i$ is the discharge current, $\Delta t$ is the discharge time and $\Delta E$ is the voltage window and $m$ is the mass of the active material in one electrode. The specific capacitances of PANI-GO are found to be 346,325 and $242 \mathrm{~F} \mathrm{~g}^{-1}$ at current densities of $0.5,1$ and $2.5 \mathrm{~A} \mathrm{~g}^{-1}$, respectively. Higher specific capacitance value $\left(242 \mathrm{~F} \mathrm{~g}^{-1}\right)$ retained even at a high discharge current density $\left(2.5 \mathrm{~A} \mathrm{~g}^{-1}\right)$ shows the superior rate capability of the PANI-GO electrode material.

The two important parameters for describing the behaviour of energy storage devices are energy density $\left(E_{\mathrm{d}}\right)$ and power density $\left(P_{\mathrm{d}}\right)$. Energy density is the energy stored per unit mass and is calculated using the formula, $E_{\mathrm{d}}=0.5 * C_{d} * V^{2}$, and the power density is the amount of energy delivered per unit mass, $P_{\mathrm{d}}=E_{\mathrm{d}}(\Delta t)^{-1}$. Energy densities of PANI-GO were found to be 17, 15 and $12 \mathrm{~W} \mathrm{~h} \mathrm{~kg}^{-1}$ at power densities of 316,632 and $1579 \mathrm{~W} \mathrm{~kg}^{-1}$, respectively. At the energy density of $15 \mathrm{~W} \mathrm{~h} \mathrm{~kg}^{-1}$, the power density of PANI-GO $\left(632 \mathrm{~W} \mathrm{~kg}^{-1}\right)$ is found to be higher than that of PANI $\left(283 \mathrm{~W} \mathrm{~kg}^{-1}\right)$.

Cycle life is an important parameter for supercapacitor applications. Cycle life for PANI-GO cell was carried in $1 \mathrm{M} \mathrm{H}_{2} \mathrm{SO}_{4}$ at two different current densities of 1 and $2.5 \mathrm{~A} \mathrm{~g} \mathrm{~g}^{-1}$ for 1000 continuous cycles. The behaviour of capacitance and equivalent series resistance (ESR) with cycle number are given in Fig. 7. The result shows that the specific capacitance is decreased to 84 and $81 \%$ of its initial values for cells operating at 1 and $2.5 \mathrm{~A} \mathrm{~g}^{-1}$, respectively. Equivalent series resistance values (ESR) with cycle numbers are calculated by dividing the ' $i R$ ' drop by the applied current density and the results are included in Fig. 7. The ESR values increased from 5 to $18 \Omega$ and 7 to $40 \Omega$ for the cells operating at 1 and $2.5 \mathrm{~A} \mathrm{~g} \mathrm{~g}^{-1}$. The decay in capacitance with cycle number is due to the repetitive volumetric expansion/contraction of PANI chains during the continuous injection/rejection (charge/ 


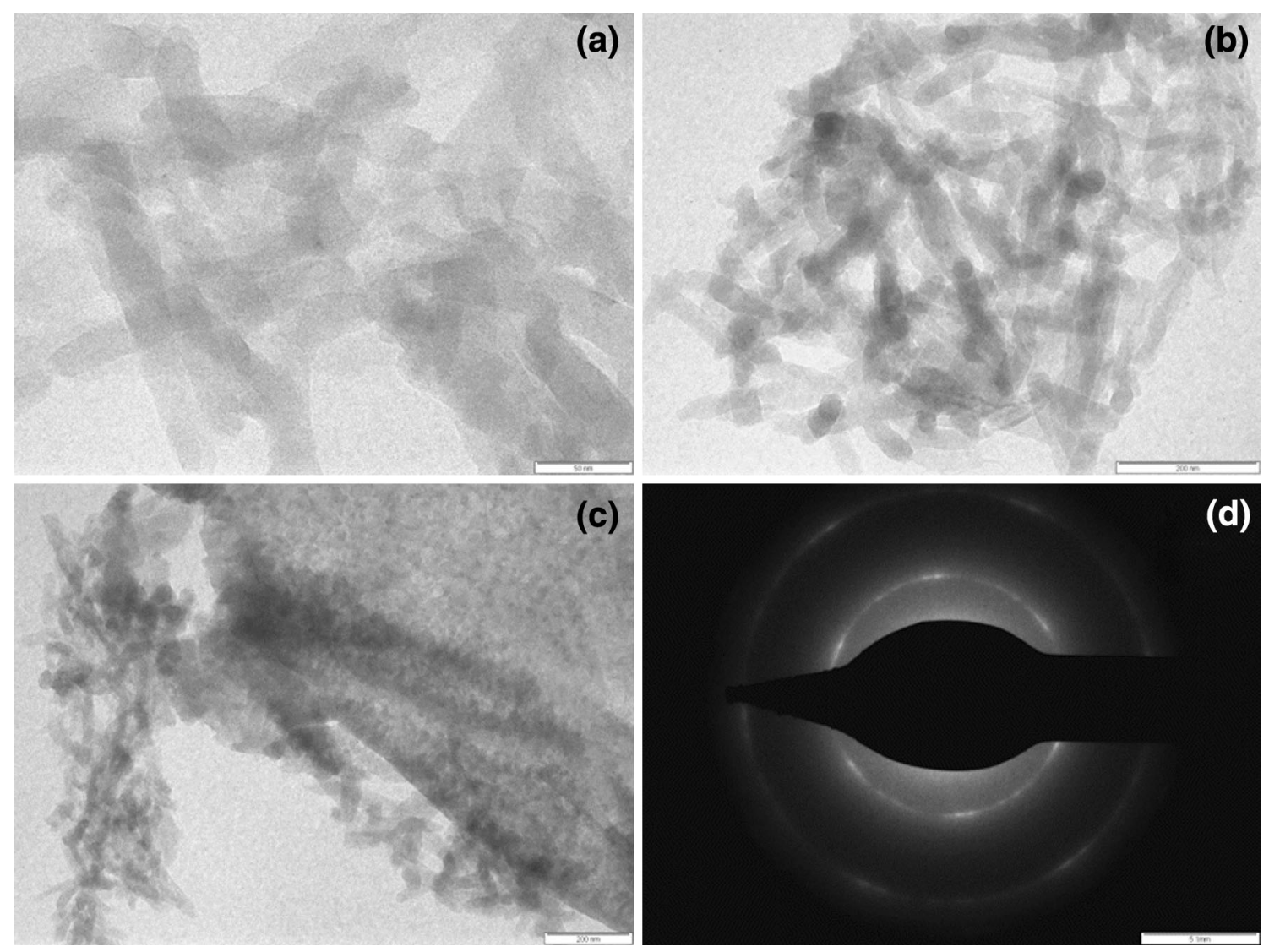

Fig. 3 a, b, c TEM pictures of PANI-GO and d SAED pattern of PANI-GO

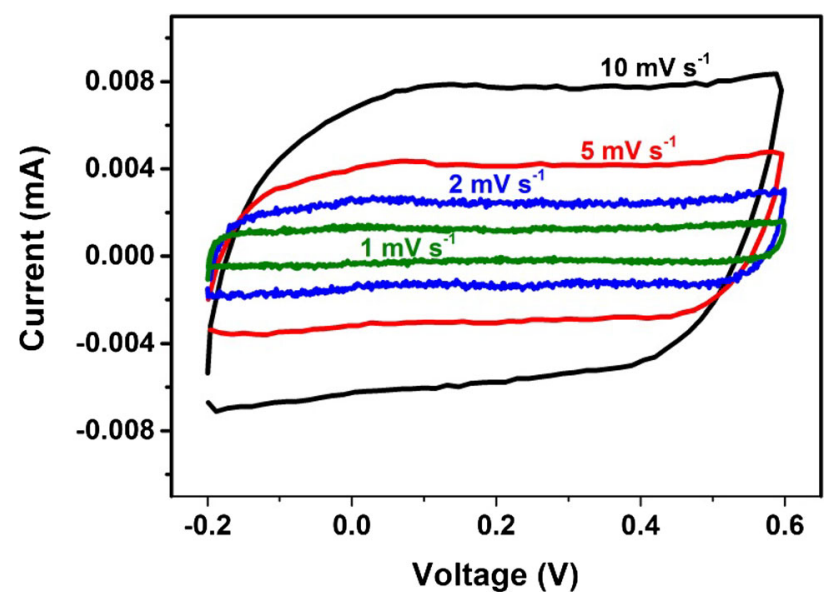

Fig. 4 Cyclic voltammograms of symmetric supercapacitor cell of PANI-GO at different sweep rates

discharge) of electrolyte ions, deteriorating the charge distribution and conformation of $\pi$ conjugated PANI chains.

To find out the frequency behaviour of PANI-GO electrode, electrochemical impedance analysis was carried out at an applied voltage of $0.6 \mathrm{~V}$ with $5 \mathrm{mV}$ amplitude in

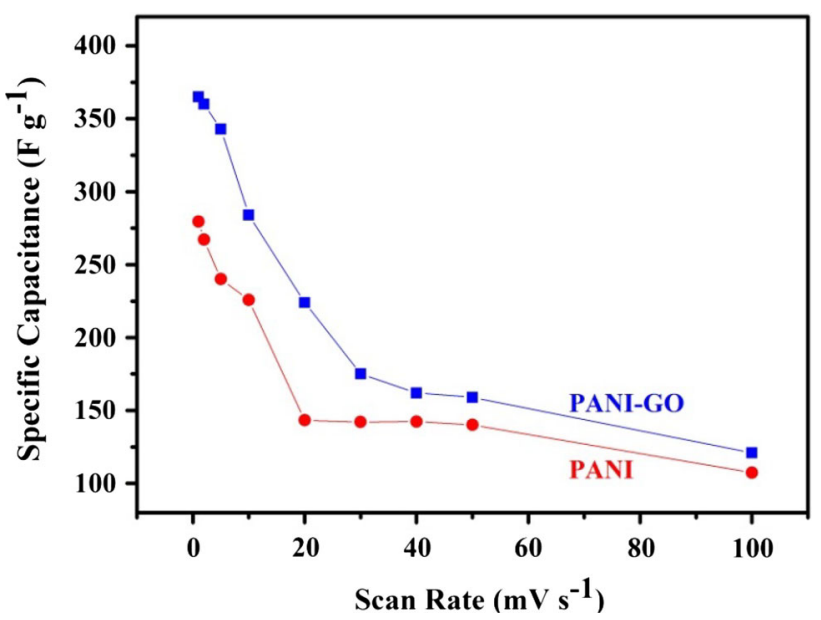

Fig. 5 Behaviour of specific capacitance at different sweep rates for PANI and PANI-GO symmetric supercapacitor cells

$1 \mathrm{MH}_{2} \mathrm{SO}_{4}$ electrolyte solution (Fig. 8). The plot consists of a depressed semicircle in the high-frequency region and a near vertical line in the low-frequency region. At the high-frequency region, the intercept with the real axis corresponds to the solution resistance $\left(R_{\mathrm{s}}\right)$ and the diameter of the semicircle provides the charge transfer resistance 


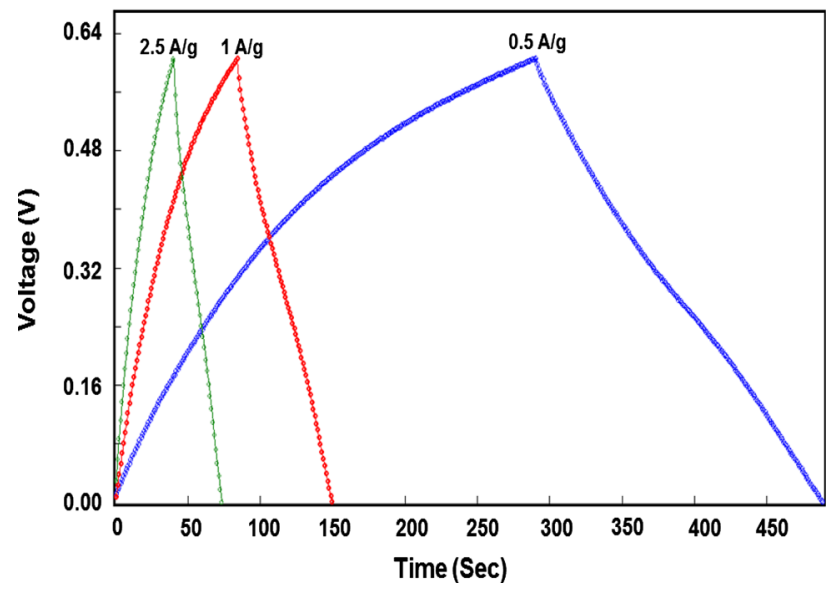

Fig. 6 Galvanostatic charge-discharge curves of PANI-GO symmetric supercapacitor cell at different current densities

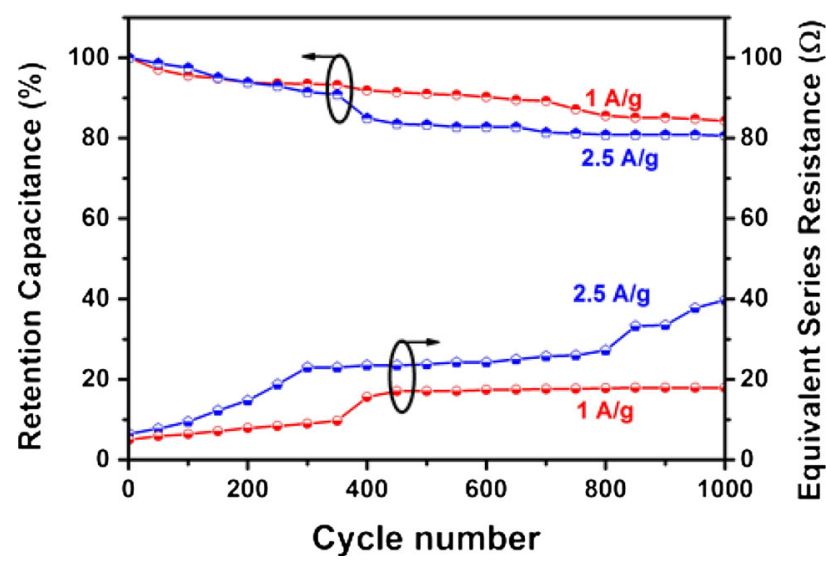

Fig. 7 Retention capacitance and ESR behaviour with cycle numbers for PANI-GO symmetric supercapacitor cell at 1 and $2.5 \mathrm{~A} \mathrm{~g}^{-1}$ current density

$\left(R_{\mathrm{ct}}\right)$.Vertical line in the low-frequency region represents the characteristic feature of the capacitive behaviour. The specific capacitance of the electrode material is calculated using the following formula.

$C_{\text {is }}=\frac{-1}{2 \pi * f * Z_{\text {im }} * m}$,

where $C_{\text {is }}$ is specific capacitance from impedance spectrum, $f$ is the frequency at the tip of the spike $(0.01 \mathrm{~Hz}), Z_{\mathrm{im}}$ is the imaginary impedance at frequency $f$ and $m$ is the mass of the active electrode material. The values of solution resistance, charge transfer resistance, double layer capacitance, time constant and specific capacitance are $0.98,10.57 \Omega$, $0.15 \mathrm{mF}, 0.95 \mathrm{~ms}$ and $240 \mathrm{~F} \mathrm{~g}^{-1}$, respectively.

Equivalent circuit was obtained by simulating the experimental Nyquist data in Zman software supplied with electrochemical work station. Equivalent circuit obtained

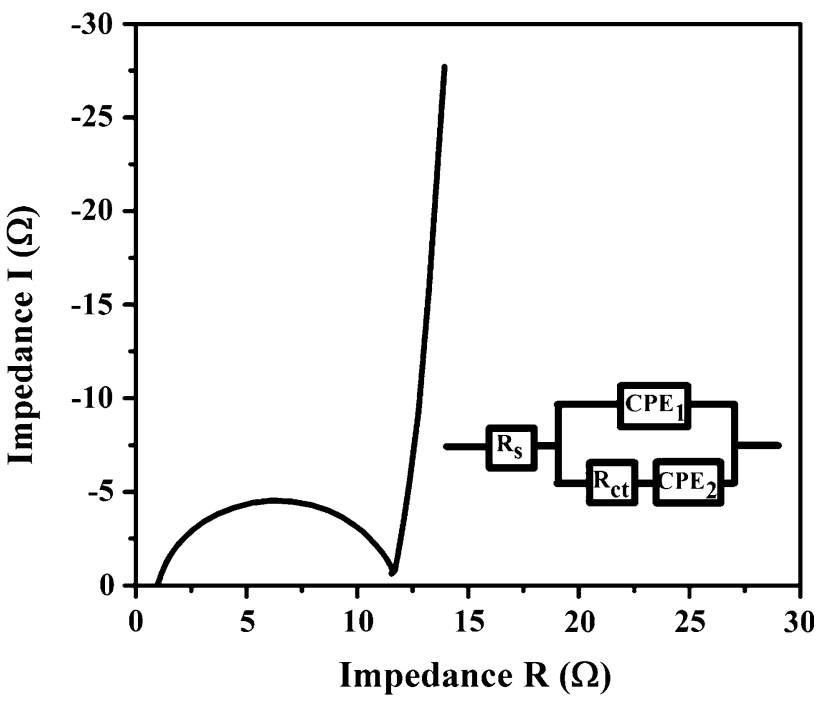

Fig. 8 Nyquist plot of PANI-GO in the frequency range of $40 \mathrm{kHz}-$ $10 \mathrm{mHz}$ at an applied potential of $0.6 \mathrm{~V}$ with circuit diagram (inset)

for PANI-GO is shown as inset in Fig. 8. The circuit elements consist of $R_{\mathrm{s}}, R_{\mathrm{ct}}, \mathrm{CPE}_{1}$ and $\mathrm{CPE}_{2}$. Here, $R_{\mathrm{s}}$ is the bulk solution resistance, $R_{\mathrm{ct}}$ is the charge transfer resistance, $\mathrm{CPE}_{1}$ and $\mathrm{CPE}_{2}$ are the constant phase elements, which originate due to the inhomogeneity of the electrode surface and other parameters. $\mathrm{CPE}_{2}$ is connected in series with $R_{\mathrm{ct}}$ and these elements are parallel to $\mathrm{CPE}_{1}$, further these components are in series with $R_{\mathrm{S}}$. The constant phase element is defined as

$\mathrm{CPE}=\frac{1}{Q(j \omega)^{n}}$,

where $Q$ is the constant value which is related to both the surface and the electroactive species, the exponent term $n$ refers to the CPE coefficient and exponent, respectively, while $o$ represents the angular frequency. The CPE exponent, $n$, ranges from -1 to 1 . Accordingly, for $n=-1,0$, 0.5 , and 1 , the CPE is equivalent to a pure inductor, a pure resistor, diffusive behaviour, and a pure capacitor, respectively. The value of $n$ for PANI-GO is found to be 0.87 which shows that it has a good capacitive behaviour. Further effective area $(A)$ of the active material on the electrode can be calculated from

$A=\frac{Q_{\mathrm{dl}}}{C_{\mathrm{Hg}}}$,

where $C_{\mathrm{Hg}}$ is the capacitance of pure mercury $\left(20 \mu \mathrm{F} \mathrm{cm}^{-2}\right)$, which is a commonly used reference parameter for determining the effective area. [28]. Following the above equation, the effective area of PANI-GO is found to be $11.1 \mathrm{~cm}^{2}$. 


\section{Conclusions}

We have employed a simple chemical polymerization route to prepare a high-performance supercapacitor electrode material of PANI-GO. XRD, FE-SEM and TEM analyses indicate that in PANI-GO composite, PANI nanofibres were intercalated into GO layers and also covered the GO. Electrochemical performance of PANI was improved by the intercalation of PANI nanofibres into GO. The values of specific capacitance, energy and power densities carried out at $0.5 \mathrm{~A} \mathrm{~g}^{-1}$ were $346 \mathrm{~F} \mathrm{~g}^{-1}, \quad 17 \mathrm{~W} \mathrm{~h} \mathrm{~kg}^{-1}$, and $316 \mathrm{~W} \mathrm{~kg}^{-1}$, respectively. PANI-GO electrode was stable even at higher discharge current of $2.5 \mathrm{~A} \mathrm{~g}^{-1}$, which showed specific capacitance, energy and power densities of $242 \mathrm{~F} \mathrm{~g}^{-1}, 12 \mathrm{~W} \mathrm{~h} \mathrm{~kg}^{-1}$, and $1579 \mathrm{~W} \mathrm{~kg}^{-1}$, respectively. Retention in specific capacitance was obtained as $84 \%$ of its original capacitance $\left(346 \mathrm{~F} \mathrm{~g}^{-1}\right)$ after 1000 charge-discharge cycles. Moreover, this material showed low solution resistance $(0.98 \Omega$ ), low ESR value (5 $\Omega$ ) and lower time constant $(0.9 \mathrm{~ms})$. Hybrid material of PANI-GO is proven as a potential electrode material for supercapacitors.

Acknowledgments The authors thank CSIR, New Delhi under the TAPSUN program (NWP-0056) for funding. We are thankful to Dr. M. Lakshmi Kantam, Director, CSIR-IICT, Hyderabad, Dr. Vijayamohanan K Pillai, Director, and Dr. S. Gopukumar, Scientist, CSIR-CECRI, Karaikudi for their valuable discussion. UM is thankful to CSIR, India for financial assistance.

Open Access This article is distributed under the terms of the Creative Commons Attribution 4.0 International License (http://crea tivecommons.org/licenses/by/4.0/), which permits unrestricted use, distribution, and reproduction in any medium, provided you give appropriate credit to the original author(s) and the source, provide a link to the Creative Commons license, and indicate if changes were made.

\section{References}

1. Wang, G., Zhang, L., Zhang, J.: A review of electrode materials for electrochemical supercapacitors. Chem. Soc. Rev. 41, 797-828 (2012)

2. Uppugalla, S., Male, U., Srinivasan, P.: Design and synthesis of heteroatoms doped carbon/polyaniline hybrid material for high performance electrode in supercapacitor application. Electrochim. Acta 146, 242-248 (2014)

3. Geniès, E.M., Boyle, A., Lapkowski, M., Tsintavis, C.: Polyaniline: a historical survey. Synth. Met. 36, 139-182 (1990)

4. Dhand, C., Das, M., Datta, M., Malhotra, B.D.: Recent advances in polyaniline based biosensors. Biosens. Bioelectron. 26, 2811-2821 (2011)

5. Snook, G.A., Kao, P., Best, A.S.: Conducting-polymer-based supercapacitor devices and electrodes. J. Power Sources 196, 1-12 (2011)

6. Singu, B.S., Male, U., Srinivasan, P., Pabba, S.: Use of surfactant in aniline polymerization with $\mathrm{TiO} 2$ to PANI-TiO2 for supercapacitor performance. J. Solid State Electrochem. 18, 1995-2003 (2014)
7. Wang, H., Hao, Q., Yang, X., Lu, L., Wang, X.: Effect of graphene oxide on the properties of its composite with polyaniline. ACS Appl. Mater. Interfaces 2, 821-828 (2010)

8. Wang, H., Hao, Q., Yang, X., Lu, L., Wang, X.: Graphene oxide doped polyaniline for supercapacitors. Electrochem. Commun. 11, 1158-1161 (2009)

9. Yan, X., Chen, J., Yang, J., Xue, Q., Miele, P.: Fabrication of free-standing, electrochemically active, and biocompatible graphene oxide-polyaniline and graphene-polyaniline hybrid papers. ACS Appl. Mater. Interfaces 2, 2521-2529 (2010)

10. Wei, H., Zhu, J., Wu, S., Wei, S., Guo, Z.: Electrochromic polyaniline/graphite oxide nanocomposites with endured electrochemical energy storage. Polymer 54, 1820-1831 (2013)

11. Zhu, J., Chen, M., Qu, H., Zhang, X., Wei, H., Luo, Z., Colorado, H., Wei, S., Guo, Z.: Interfacial polymerized polyaniline/graphite oxide nanocomposites toward electrochemical energy storage. Polymer 53, 5953-5964 (2012)

12. Liu, Y., Deng, R., Wang, Z., Liu, H.: Carboxyl-functionalized graphene oxide-polyaniline composite as a promising supercapacitor material. J. Mater. Chem. 22, 13619-13624 (2012)

13. Shulga, Y.M., Baskakov, S.A., Abalyaeva, V.V., Efimov, O.N., Shulga, N.Y., Michtchenko, A., Lartundo-Rojas, L., Moreno, L.A., Cabanas-Moreno, J.G., Vasilets, V.N.: Composite material for supercapacitors formed by polymerization of aniline in the presence of graphene oxide nanosheets. J. Power Sources 224, 195-201 (2013)

14. Luo, Z., Zhu, L., Zhang, H., Tang, H.: Polyaniline uniformly coated on graphene oxide sheets as supercapacitor material with improved capacitive properties. Mater. Chem. Phys. 139, 572-579 (2013)

15. Zhang, Q., Li, Y., Feng, Y., Feng, W.: Electropolymerization of graphene oxide/polyaniline composite for high-performance supercapacitor. Electrochim. Acta 90, 95-100 (2013)

16. Xu, J., Wang, K., Zu, S., Han, B., Wei, Z.: Hierarchical nanocomposites of polyaniline nanowire arrays on graphene oxide sheets with synergistic effect for energy storage. ACS Nano 4, 5019-5026 (2010)

17. Xu, G., Wang, N., Wei, J., Lv, L., Zhang, J., Chen, Z., Xu, Q.: Preparation of graphene oxide/polyaniline nanocomposite with assistance of supercritical carbon dioxide for supercapacitor electrodes. Ind. Eng. Chem. Res. 51, 14390-14398 (2012)

18. Xu, D.D., Xu, Q., Wang, K.X., Chen, J., Chen, Z.M.: Fabrication of free-standing hierarchical carbon nanofiber/graphene oxide/ polyaniline films for supercapacitors. ACS Appl. Mater. Interfaces 6, 200-209 (2014)

19. Gui, D., Liu, C., Chen, F., Liu, J.: Preparation of polyaniline/graphene oxide nanocomposite for the application of supercapacitor. Appl. Surf. Sci. 307, 172-177 (2014)

20. Khomenko, V., Frackowiak, E., Béguin, F.: Determination of the specific capacitance of conducting polymer/nanotubes composite electrodes using different cell configurations. Electrochim. Acta 50, 2499-2506 (2005)

21. Xu, C., Sun, J., Gao, L.: Synthesis of novel hierarchical graphene/ polypyrrole nanosheet composites and their superior electrochemical performance. J. Mater. Chem. 21, 11253-11258 (2011)

22. Huang, J., Virji, S., Weiller, B.H., Kaner, R.B.: Polyaniline nanofibers: facile synthesis and chemical sensors. J. Am. Chem. Soc. 125, 314-315 (2002)

23. Huang, J.X., Kaner, R.B.: A general chemical route to polyaniline nanofibers. J. Am. Chem. Soc. 126, 851-855 (2004)

24. Zhang, J., Zhao, X.: Conducting polymers directly coated on reduced graphene oxide sheets as high-performance supercapacitor electrodes. J. Phys. Chem. C 116, 5420-5426 (2012)

25. Lindfors, T., Latonen, R.M.: Improved charging/discharging behavior of electropolymerized nanostructured composite films 
of polyaniline and electrochemically reduced graphene oxide. Carbon 69, 122-131 (2014)

26. Zhou, H., Chen, H., Luo, S., Lu, G., Wei, W., Kuang, Y.: The effect of the polyaniline morphology on the performance of polyaniline supercapacitors. J. Solid State Electrochem. 9, 574-580 (2005)

27. Male, U., Singu, B.S., Srinivasan, P.: Aqueous, interfacial, and electrochemical polymerization pathways of aniline with thiophene: nano size materials for supercapacitor. J. Appl. Polym. Sci. 132, n/a-n/a (2015)

28. Xu, P., Han, X.J., Zhang, B., Mack, N.H., Jeon, S.H., Wang, H.L.: Synthesis and characterization of nanostructured polypyrroles: morphology-dependent electrochemical responses and chemical deposition of Au nanoparticles. Polymer 50, 2624-2629 (2009) 